\title{
Intramural duodenal hematoma secondary to pancreatitis: case report and review of the literature
}

\author{
João Henrique Botto de Oliveira', Raiza Samenica Esper', Rodrigo Campos Ocariz', Flora Specian Sartori', Lucas Marcelo Dias \\ Freire", Elinton Adami Chaim "', Francisco Callejas-Neto"v, Everton Cazzov
}

Department of Surgery, Centro Médico de Campinas (CMC), Campinas (SP), Brazil

'MD. Resident Physician, Department of Surgery, Centro Médico de Campinas (CMC), Campinas (SP), Brazil

"MD. Attending Physician, Endovascular Surgery Unit, Centro Médico de Campinas (CMC), Campinas (SP), Brazil

"'MD, PhD. Full Professor, Department of Surgery, Faculdade de Ciências Médicas da Universidade Estadual de Campinas (FCM/UNICAMP),

Campinas (SP), Brazil.

"MD, MSc. Assistant Professor, Department of Surgery, Faculdade de Ciências Médicas da Universidade Estadual de Campinas (FCM/ UNICAMP), Campinas (SP), Brazil.

'MD, PhD. Adjunct Professor, Department of Surgery, Faculdade de Ciências Médicas da Universidade Estadual de Campinas (FCM/ UNICAMP), Campinas (SP), Brazil.

\section{KEY WORDS:}

Pancreatitis.

Duodenum.

Hematoma.

Embolization, therapeutic.

Duodenal diseases.

\begin{abstract}
CONTEXT: Spontaneous intramural duodenal hematoma is uncommon and is usually associated with coagulopathy, anticoagulant therapy and endoscopic procedures. The aim here was to describe a case of intramural duodenal hematoma caused by chronic exacerbation of pancreatitis.

CASE REPORT: A 46-year-old male with chronic alcoholic pancreatitis was admitted to hospital due to abdominal pain, melena and low hemoglobin. An intramural duodenal hematoma with active bleeding was detected and selective angioembolization was warranted. The patient evolved with a perforated duodenum and underwent laparotomy with exclusion of the pylorus and Roux-en-Y gastrojejunostomy. He was discharged nine days later.

CONCLUSION: Intramural duodenal hematoma is a rare complication of pancreatitis. Selective embolization is the preferred treatment for hemorrhagic complications of pancreatitis. However, the risk of visceral ischemia and perforation should be considered.
\end{abstract}

\section{INTRODUCTION}

The first description of an intramural duodenal hematoma was made by McLauchlan in 1838 . This condition is usually associated with blunt abdominal trauma. Spontaneous intramural duodenal hematoma is uncommon and has been linked to coagulopathy, anticoagulant therapy and endoscopic procedures. ${ }^{1-3}$ Other causes include several pancreatic diseases, collagenosis, peptic ulcers and pancreaticoduodenal aneurysm. ${ }^{4-7}$ To date, the exact mechanism leading to intramural hematoma in cases of pancreatitis has not yet been fully elucidated and the prognosis has not yet been completely defined, mainly due to its scarcity. ${ }^{1,3,5-9}$

This study sought to describe a case of an intramural duodenal hematoma caused by chronic exacerbation of pancreatitis.

\section{CASE REPORT}

The patient (JCAP) was a 43-year-old white male who had been a chronic abuser of alcohol for 25 years (two liters of distilled liquor/day), with an antecedent of acute pancreatitis five years before the present case report. He had been complaining of strong typical pain for three days, along with melena.

At admission to hospital, the following test results were noted: leukogram $=15,000 \mathrm{u} / \mathrm{l}$, hemoglobin $=16 \mathrm{~g} / \mathrm{dl}$ and amylase $=99 \mathrm{IU} / \mathrm{l}$. A computed tomography (CT) scan showed signs of chronic pancreatitis and a bulky submucosal duodenal hematoma from the bulb to the third portion of the duodenum with intramural active bleeding in the region of the gastroduodenal artery (Figure 1A). Upper digestive tract endoscopy revealed a large submucosal hematoma in the duodenum, without any active bleeding into the lumen (Figure 2).

On the following day, the hemoglobin level decreased to $12 \mathrm{~g} / \mathrm{dl}$ and selective angioembolization was indicated. During angiography, active bleeding was detected (Figure 3A). After embolization, no more signs of active bleeding were observed (Figure 3B). 


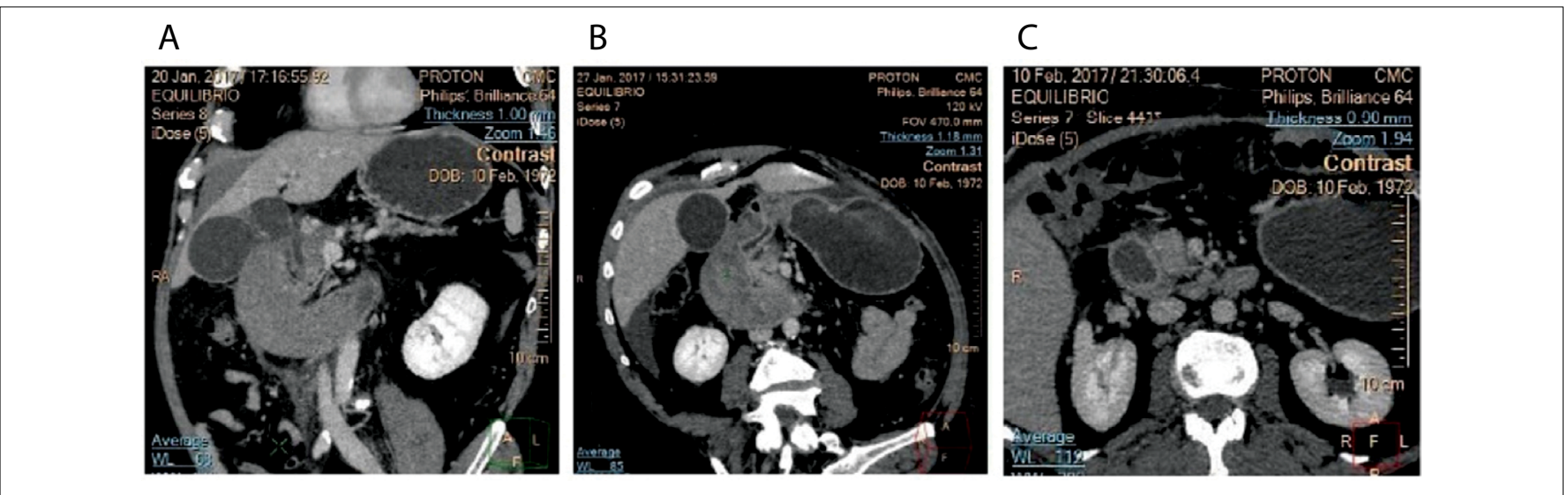

Figure 1. Computed tomography scans: A) at admission; B) post-embolization; C) post-surgical control.

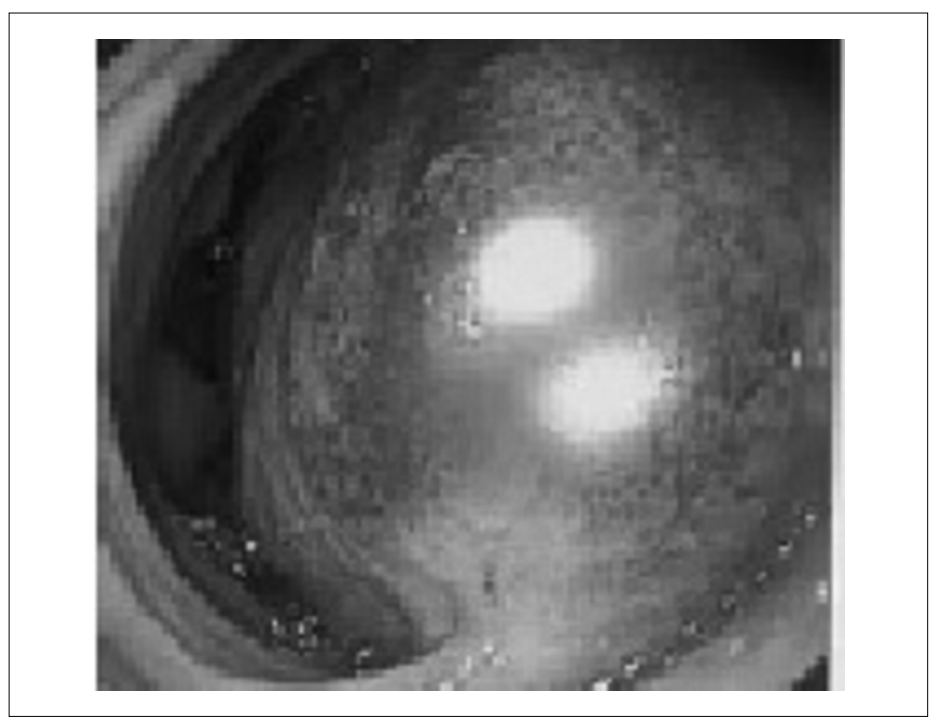

Figure 2. Upper gastrointestinal endoscopy.

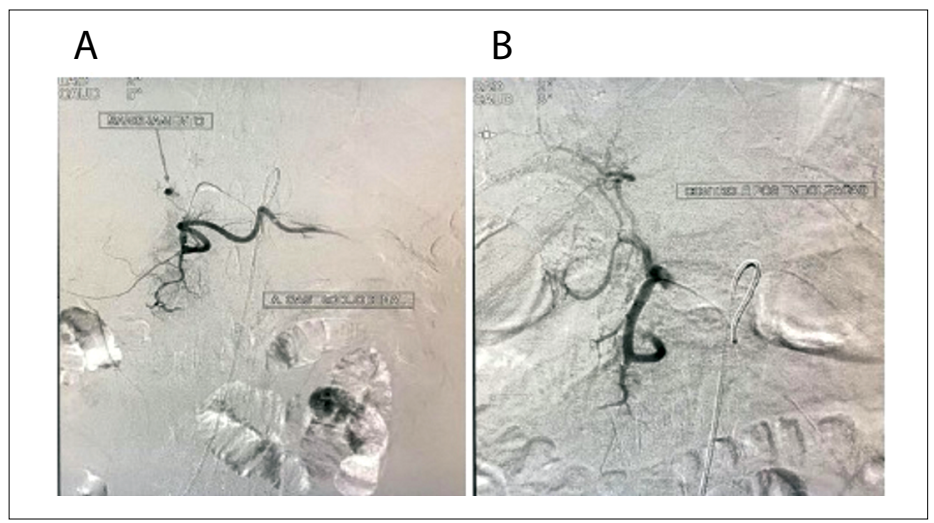

Figure 3. Arterial embolization: A) active bleeding in the region of the gastroduodenal artery; B) post-embolization control.

One day after this procedure, there was worsening of the pain. A CT scan showed signs of visceral perforation (Figure 1B). Emergency laparotomy was warranted and revealed the following: an ischemic duodenum with a bulky wall hematoma and a $6-\mathrm{cm}$ duodenal rupture from the bulb to the second portion of the duodenum, along with signs of acute pancreatitis. The duodenal rupture was closed, along with exclusion of the pylorus, and Rouxen-Y gastroenteroanastomosis was carried out.

The patient then progressed with a high-output duodenal fistula. Treatment consisting of parenteral nutrition, octreotide and antibiotic therapy was started, and this led to regression over a nine-day period. A control CT scan demonstrated regression of the hematoma, while the signs of chronic pancreatitis continued to be present, but without evidence of exacerbation (Figure 1C). A contrasted upper gastrointestinal radiographic series showed exclusion of the pylorus and patent gastroenteroanastomosis. The patient was then followed up for six months, with uneventful evolution.

\section{DISCUSSION}

Duodenal hematomas have been described as complications of both acute and chronic pancreatitis. Acute pancreatitis is a common disease, with an incidence of 20 to 40 cases/100,000 personyears of life and a mortality rate close to $5 \%$, and the vast majority of the cases are of biliary etiology. ${ }^{10}$ On the other hand, chronic pancreatitis is a progressive inflammatory disorder characterized by irreversible destruction of the pancreatic parenchyma and may

Table 1. Database search results for duodenal hematomas caused by pancreatitis

\begin{tabular}{|c|c|c|}
\hline Electronic databases & Search strategies & Results \\
\hline MEDLINE (PubMed) & $\begin{array}{c}\text { (Duodenum) AND } \\
\text { (Hematoma) AND } \\
\text { (Pancreatitis) }\end{array}$ & 13 case reports \\
\hline LILACS (BVS) & $\begin{array}{c}\text { (((Duodenum) OR } \\
\text { (Duodeno)) AND } \\
\text { (Hematoma) AND } \\
\text { ((Pancreatitis) OR } \\
\text { (Pancreatite) OR } \\
\text { (Pancreatítis))) }\end{array}$ & 1 case report \\
\hline
\end{tabular}


Table 2. Previously reported cases of intramural duodenal hematoma secondary to pancreatitis ${ }^{1-9,12-16}$

\begin{tabular}{|c|c|c|c|c|c|c|}
\hline Author & $\begin{array}{c}\text { Age } \\
\text { (years) }\end{array}$ & Gender & $\begin{array}{l}\text { Etiology of } \\
\text { pancreatitis }\end{array}$ & $\begin{array}{l}\text { Anticoagulant/ } \\
\text { antiplatelet } \\
\text { therapy or } \\
\text { coagulopathy }\end{array}$ & Treatment & Outcome \\
\hline
\end{tabular}

$\begin{array}{lllll}\text { Bodnár et al. } & & & & \\ & & \text { Male } & \text { Hypertriglyceridemia } & \text { No }\end{array}$

Evolved with a pancreatic abscess 33 Male Hypertriglyceridemia that required CT-guided aspiration; no specific therapy for the duodenal hematoma; discharged after six weeks

\begin{tabular}{|c|c|c|c|c|c|c|}
\hline Leundji et al. ${ }^{2}$ & 45 & Male & Alcoholic & $\begin{array}{l}\text { Yes } \\
\text { (thrombopenic } \\
\text { due to portal } \\
\text { hypertension) }\end{array}$ & Conservative & Asymptomatic one year afterwards \\
\hline $\begin{array}{l}\text { Eurboonyanun } \\
\text { et al. }{ }^{3}\end{array}$ & 27 & Male & Alcoholic & No & Conservative & Uneventful; discharged after 17 days \\
\hline $\begin{array}{l}\text { Fukunaga } \\
\text { et al. } .^{5}\end{array}$ & 49 & Male & Alcoholic & No & $\begin{array}{l}\text { Surgical drainage and } \\
\text { biopsy }\end{array}$ & Uneventful; discharged after 18 days \\
\hline Lee et al. ${ }^{7}$ & 47 & Male & Dengue fever & $\begin{array}{l}\text { Yes (dengue } \\
\text { hemorrhagic } \\
\text { fever) }\end{array}$ & Conservative & $\begin{array}{c}\text { Evolved with a peripancreatic abscess } \\
\text { that required drainage } 51 \text { days after } \\
\text { admission; uneventful evolution after } \\
\text { drainage }\end{array}$ \\
\hline Lee et al. ${ }^{8}$ & 55 & Male & Alcoholic & No & Endoscopic drainage & $\begin{array}{c}\text { Uneventful after drainage; follow-up } \\
\text { CT demonstrated a smaller intramural } \\
\text { mass in the duodenum and upper } \\
\text { endoscopy showed a small duodenal } \\
\text { ulcer }\end{array}$ \\
\hline
\end{tabular}

clopidogrel due

Veloso et al.

to a previous $\quad$ Conservative Uneventful; discharged after 14 days myocardial infarction)

\begin{tabular}{|c|c|c|c|c|c|c|}
\hline Ma et al. ${ }^{12}$ & 32 & Male & Alcoholic & No & $\begin{array}{l}\text { Pancreaticoduodenectomy } \\
\text { after failure of conservative } \\
\text { therapy }\end{array}$ & $\begin{array}{c}\text { Discharged two weeks after surgery; } \\
\text { uneventful late postoperative } \\
\text { evolution }\end{array}$ \\
\hline Khurana et al. ${ }^{14}$ & 73 & Female & $\begin{array}{l}\text { Pancreatic } \\
\text { malignancy }\end{array}$ & $\begin{array}{l}\text { Yes (warfarin for } \\
\text { deep venous } \\
\text { thrombosis) }\end{array}$ & Conservative & $\begin{array}{c}\text { Uneventful; after resolution of } \\
\text { duodenal hematoma, the patient } \\
\text { underwent distal pancreatic resection }\end{array}$ \\
\hline Farhoud et al. ${ }^{15}$ & 71 & Female & Obstructive & $\begin{array}{l}\text { Yes (warfarin for } \\
\text { deep venous } \\
\text { thrombosis) }\end{array}$ & Conservative & Uneventful; discharged after 10 days \\
\hline $\begin{array}{l}\text { Fesenmeyer } \\
\text { et al. } .^{16}\end{array}$ & 71 & Male & Unknown & No & Conservative & Uneventful \\
\hline
\end{tabular}

$\mathrm{CT}=$ computed tomography. 


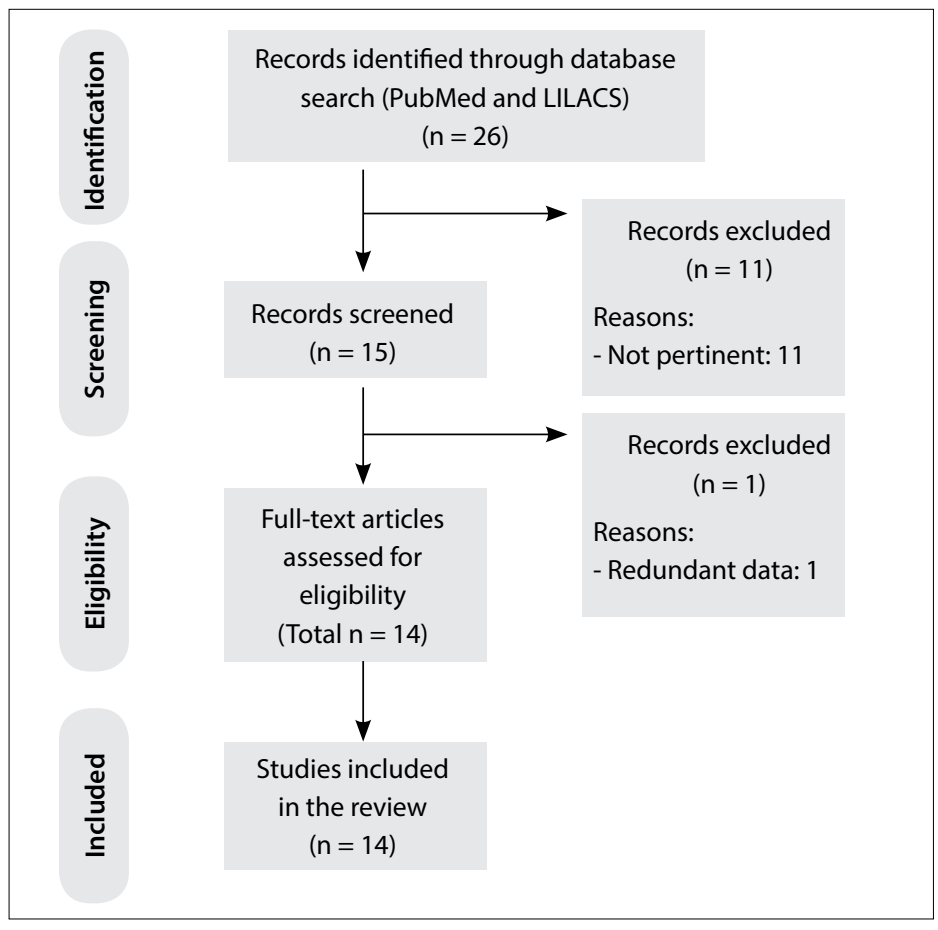

Figure 4. Flow diagram of the narrative review of the literature.

be associated with disabling chronic pain and permanent loss of exocrine and endocrine function. The majority of such cases are alcohol-related. Their prevalence is 3-4 cases/100,000 people. ${ }^{11}$

One of the rarest and most fatal complications of pancreatitis is spontaneous bleeding of intestinal vessels. A review of the literature was conducted through an online search for the MeSH terms "duodenum", "hematoma" and "pancreatitis" in MEDLINE (via PubMed) and LILACS (via BVS) in papers published over the last 20 years (Table 1). We included original studies that reported single cases or case series of this disease. All the papers were checked according to their titles and abstracts (screening). Full papers were obtained from journals available through the website of the Commission for Improvement of Higher Education Personnel (Comissão de Aperfeiçoamento de Pessoal de Nível Superior, CAPES), of the Brazilian Ministry of Education. Articles that were unavailable were requested from their authors. Articles presenting potentially relevant studies were read and analyzed to assess the inclusion criteria. We excluded articles that consisted of in vitro or animal studies, articles in which the participants' characteristics did not match those mentioned above, poster session abstracts, review articles and other types of publications. Articles that described traumatic or iatrogenic duodenal hematomas were also excluded. Other papers were used for contextualization and discussion.

After extensive online research, we identified 14 studies, which were all single case reports. Table $2^{1-9,12-16}$ summarizes the main articles found and their reported outcomes. Figure 4 presents a flow diagram of the articles selected.
Vascular erosion occurs due to extravasation of proteolytic enzymes. Potentially fatal bleeding, characterized by a decrease of two hemoglobin points, are rare complications occurring in about $1 \%$ to $5 \%$ of patients with acute or chronic pancreatitis. The vessels most affected are the gastroduodenal, pancreatoduodenal, splenic, gastroepiploic and left gastric arteries, because of their proximity to the pancreas, along with small branches of the inferior mesenteric arteries. The symptoms include pain, melena, hematemesis and retroperitoneal bleeding. Upper endoscopy, CT scans and angiography are involved in making the diagnosis. ${ }^{17}$

The majority of the previously reported cases showed that conservative therapy was possible, but this method is associated with lengthier hospital stay and a need for transfusion of blood components. Interventional therapies may include surgical repair using endoscopic and endovascular techniques. The benefits of endoscopy include its minimally invasive nature, compared with other treatment options, and the absence of radiation exposure. However, it has limitations, given that it cannot be used for areas of bleeding that are inaccessible to the intestinal lumen. ${ }^{8}$ Arterial embolization seems to be effective for management of bleeding. Embolization is considered successful when both radiologically and clinically there is evidence of bleeding control characterized by hemoglobin stabilization and absence of signs and symptoms of shock. ${ }^{18,19}$ Laparotomy for bleeding therapy should only be considered for hemodynamically unstable patients. Advances in endovascular radiology have led to this method becoming the preferred treatment option. ${ }^{18}$

The present case demonstrates the need for a high degree of suspicion that the diagnosis could comprise bleeding caused by pancreatitis, as well as the need to remain open to the possibility of a severe and rare complication after embolization (visceral perforation). This complication requires rapid intervention, because the risk of mortality that it presents is up to 10 times greater than that commonly observed in cases of acute pancreatitis. ${ }^{20,21}$ The currently available evidence consists solely of single case reports, which thus precludes final conclusions regarding the optimal therapy. Hence, further research is necessary.

\section{CONCLUSION}

Intramural duodenal hematoma is a rare complication of pancreatitis. Selective embolization is the preferred treatment, but the risk of visceral ischemia and perforation should be considered.

\section{REFERENCES}

1. Bodnár Z, Várvölgyi C, Tóth J, Sápy P, Kakuk G. Intramural duodenal hematoma complicating acute necrotizing pancreatitis. Gastrointest Endosc. 2000;52(6):791-3.

2. Leundji H, Cuingnet P, Simon M, Boruchowicz A. [Duodenal hematoma associated with thrombopenia in chronic alcoholic pancreatitis]. Gastroenterol Clin Biol. 2002;26(2):185-6. 
3. Eurboonyanun C, Somsap K, Ruangwannasak S, Sripanaskul A. Spontaneous Intramural Duodenal Hematoma: Pancreatitis, Obstructive Jaundice, and Upper Intestinal Obstruction. Case Rep Surg. 2016;2016:5321081.

4. Dugernier TL, Breuskin FM. Duodenal air dissection secondary to intramural hematoma in necrotizing pancreatitis. Endoscopy. 2002;34(12):1024.

5. Fukunaga N, Ishikawa M, Yamamura Y, Ichimori T, Sakata A. Spontaneous intramural duodenal hematoma complicating acute pancreatitis. Surgery. 2011;149(1):143-4.

6. Neuzillet C, Facchiano E, Palazzo L, et al. Intramural duodenal hematoma as a complication of paraduodenal pancreatitis. Clin Res Hepatol Gastroenterol. 2011;35(2):140-2.

7. Lee CY, Tsai HC, Lee SS, et al. Dengue hemorrhagic fever presenting with hemorrhagic pancreatitis and an intramural hematoma of the duodenal wall: a case report and review of the literature. Southeast Asian J Trop Med Public Health. 2013;44(3):400-8.

8. Lee JY, Chung JS, Kim TH. Successful endoscopic decompression for intramural duodenal hematoma with gastric outlet obstruction complicating acute pancreatitis. Clin Endosc. 2012;45(3):202-4.

9. Veloso N, Amaro P, Ferreira M, Romãozinho JM, Sofia C. Acute pancreatitis associated with a nontraumatic, intramural duodenal hematoma. Endoscopy. 2013;45 Suppl 2 UCTN:E51-2.

10. Forsmark ChE, Vege SS, Wilcox CM. Acute Pancreatitis. N Engl J Med. 2017;376(6):598-9.

11. Gestic MA, Callejas-Neto F, Chaim EA, et al. Tratamento cirúrgico da pancreatite crônica com a técnica de Frey: panorama atual [Surgical treatment of chronic pancreatitis with frey procedure: current situation]. ABCD Arq Bras Cir Dig. 2011;24(4):305-11.

12. Ma JK, Ng KK, Poon RT, Fan ST. Pancreatic-induced intramural duodenal haematoma. Asian J Surg. 2008;31(2):83-6.

13. Dubois J, Guy F, Porcheron J. A pancreatic-induced intramural duodenal hematoma: a case report and literature review. Hepatogastroenterology. 2003;50(53):1689-92.

14. Khurana T, Shah A, Ali I, Islam R, Siddiqui AA. Intramural Duodenal Hematoma with Acute Pancreatitis in a Patient with an Overt Pancreatic Malignancy. ACG Case Rep J. 2014;1 (4):209-11.

15. Farhoud S, Stephani SM, Bromberg SH. Pancreatite aguda devida a hematoma intramural do duodeno por uso de anticoagulante [Acute pancreatitis due to intramural hematoma of the duodenum by the use of anticoagulants]. Arq Gastroenterol. 2001;38(1):53-6.

16. Fesenmyer ME, Nelson DB. Intramural duodenal hematoma due to pancreatitis. J Clin Gastroenterol. 1998;26(4):350-2.

17. Vujic I. Vascular complications of pancreatitis. Radiol Clin North Am. 1989;27(1):81-91.
18. Fitzpatrick J, Bhat R, Young JA. Angiographic embolization is an effective treatment of severe hemorrhage in pancreatitis. Pancreas. 2014;43(3):436-9.

19. Phillip V, Rasch S, Gaa J, Schmid RM, Algül H. Spontaneous bleeding in pancreatitis treated by transcatheter arterial coil embolization: a retrospective study. PLoS One. 2013;8(8):e72903.

20. Kim SI, Jin YJ, Cho SG, et al. Duodenal perforation and esophageal ischemia following transarterial chemoembolization for hepatocellular carcinoma: A case report. Medicine (Baltimore). 2016;95(27):e3987.

21. Cheah WK, So J, Chong SM, Goh P. Duodenal ulcer perforation following cyanoacrylate injection. Endoscopy. 2000;32(5):S23.

\section{Sources of funding: None \\ Conflict of interest: None}

Date of first submission: May 2, 2017

Last received: May 2, 2017

Accepted: May 29, 2017

\section{Address for correspondence:}

Everton Cazzo

Departamento de Cirurgia da Facudade de Ciências Médicas da Universidade Estadual de Campinas (FCM/UNICAMP)

Rua Alexander Fleming, s/no

Cidade Universitária Zeferino Vaz - Campinas (SP) - Brasil

CEP 13085-000

Tel. (+55 19) 3521-9450

E-mail: notrevezzo@yahoo.com.br 